\title{
PERCEPÇÕES E AVALIAÇÃO DO SETOR EMPRESARIAL A RESPEITO DE POSSIBILIDADES DE TRIPLICE HELICE COM UMA IFES INTERIORIZADA
}

\author{
J. A. V. B. MELLO*, R. A. VIANA, F. M. MELO e C. F. S. MONTEIRO \\ Centro Federal de Educação Tecnológica Celso Suckow da Fonseca \\ joseavbm@yahoo.com.br*
}

Artigo submetido em outubro/2014 e a ceito em janeiro/2016

DOI: $10.15628 /$ holos.2016.2483

\section{RESUMO}

O objetivo deste artigo é o de avaliar as percepções e avaliação do setor empresarial a respeito de possibilidades de Triplice Helice com uma IFES interiorizada, seja em pesquisa, desenvolvimento de tecnologia ou oferta de mão de obra em Engenharia de Produção. A coleta de dados está amparada na aplicação de questionários, considerando-se um estudo multicasos com 10 empresas situadas no município de Nova Iguaçu. O estudo abrangeu os três segmentos (Indústria, Comércio e Serviços), conferindo preferência pelas empresas de grande e médio porte. As empresas estudadas foram escolhidas seguindo o critério da amostragem por representatividade qualitativa. Como resultados, há de se destacar que ainda há aquelas que desconhecem a existência de cursos de nível superior na unidade, entretanto o motivo de maior interesse das empresas em estabelecer as relações de parceria com o CEFET de Nova Iguaçu, segundo os resultados da pesquisa, é ter acesso a recursos humanos qualificados na universidade.

PALAVRAS-CHAVE: universidade, empresas, cooperação.

\section{PERCEPTIONS AND EVALUATION OF THE SECTOR CORPORATE ABOUT TRIPLE HELIX POSSIBILITIES WITH A IFES INTERNALIZED}

\begin{abstract}
The purpose of this article is to evaluate the perceptions and evaluation of the business sector about the possibilities with the Triple Helix internalized IFES, whether in research, technology development or supply of manpower in Production Engineering. The data collection is supported by the use of questionnaires, considering a multi-case study of 10 companies located in the municipality of Nova Iguaçu. The study covered the three segments (Industry, Trade and Services), giving preference for large and medium-sized businesses. The
\end{abstract}

companies studied were chosen according to the criterion of sampling for qualitative representation. As results, As a result, there must be noted that there are still those who are unaware of the existence of upperlevel courses in the unit, however the reason for increased interest of companies to establish partnership relations with CEFET of Nova Iguaçu, according to the survey results, is to have access to qualified human resources in the university.

KEYWORDS: universities, companies, cooperation. 


\section{INTRODUÇÃO}

As universidades, principalmente as Instituições Federais de Ensino Superior (IFES), desenvolvem muitas ações sociais (extensão), geram novas tecnologias (pesquisa) e formam profissionais de qualidade tanto em nível técnico como acadêmico. No entanto, para nove et al. (2011), é possível afirmar que uma maior contribuição é necessária para atender às demandas da população onde as IFES estão inseridas, fazendo-se necessária uma maior participação no processo de desenvolvimento sustentável de suas regiões de abrangência.

O estabelecimento de relações de cooperação entre universidades e empresas é um tema que tem ganhado relevância em várias partes do mundo, não apenas em países desenvolvidos, mas também em país es emergentes como um tipo de rede capaz de gerar valor e desenvolvimento para as instituições de ensino, empresas e localidade diversas numa relação com potencial para gerar benefícios a todas as partes.

No Brasil, esta articulação entre universidades e empresas ainda é modesta, mas a movimentação para a formação destas parcerias é cada vez mais comum. $O$ interesse das indústrias nas pesquisas acadêmicas se intensifica com o aumento de dinamismo do mercado. A busca pela competitividade em um mercado que visa não somente atender às necessidades dos consumidores, como também surpreender os mesmos com os seus produtos e serviços, gera cada vez mais dependência sobre o desenvolvimento tecnológico.

O objetivo deste artigo é o de avaliar as percepções e avaliação do setor empresarial a respeito de possibilidades de Triplice Helice com uma IFES interiorizada, seja em pesquisa, desenvolvimento de tecnologia ou oferta de mão de obra em Engenharia de Produção.

Todos os esforços desta pesquisa serão dados na avaliação de como o relacionamento entre as empresas de Nova Iguaçu com uma Instituição de Ensino Superior do Governo Federal situada nesta mesma cidade pode gerar desenvolvimento local e criar novas oportunidades no mercado de trabalho.

\section{REVISÃO BIBLIOGRÁFICA}

\subsection{Tríplice Hélice}

O argumento da Tríplice Hélice surgiu da necessidade de formular um modelo de interação entre as três esferas responsáveis pelo processo de inovação: Universidade, Governo e o setor Empresarial.

Segundo a figura 1, o modelo desenvolvido por Etzkowitz e Leydesdorff indica que as triplas hélices podem ser vistas em três estágios: 


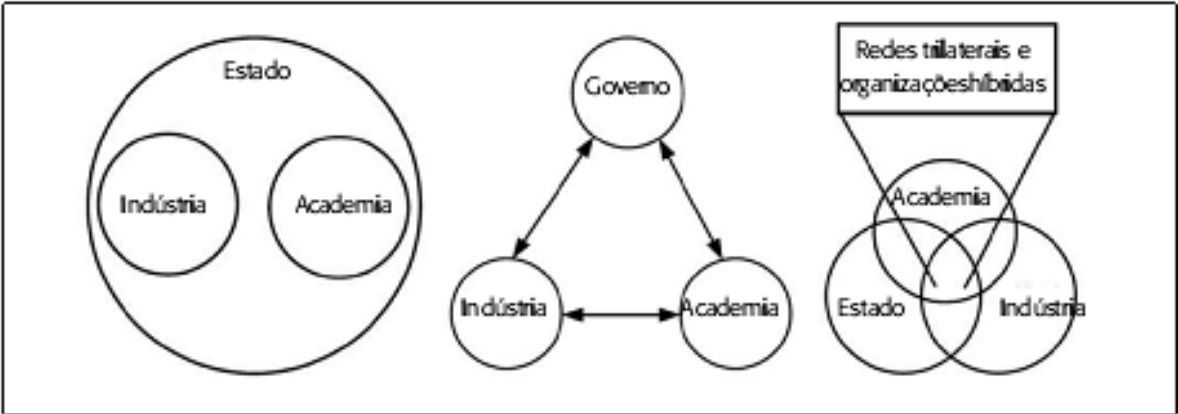

Figura 1: Representações dos 3 estágios de desenvolvimento da Tríplice Hélice Fonte: DOSSA e SEGATTO, 2010

O primeiro modelo de Tripla Hélice apresentado é chamado de Modelo Estadista de Cooperação U-E. Nele, o Governo engloba as Universidades (Academia) e as Empresas (Indústria), esquematizando as cooperações e direcionando as relações a serem estabelecidas. Segundo Noveli e Segatto (2012) a versão mais forte deste modelo pode ser encontrada na antiga União Soviética e no governo oriental (como o da China), o qual recebe o nome de Socialismo Existente.

A segunda Tripla Hélice apresenta clara separação das esferas institucionais, com a presença de fronteiras de atuação e forte interação entre as mesmas. Para Kato (2008), as hélices podem ser interpretadas como sistemas de comunicação, que consistem em operações de mercado, inovação tecnológica e a gestão de interfaces que possibilitem novas interações entre os vértices do esquema em triângulo, apoiando-se em uma legislação de patentes. A representação é também chamada de modelo Laissez-faire.

Na terceira Tripla Hélice, segundo Cunha e Neves (2008) os agentes estão sobrepostos para demonstrar a forte interação entre os mesmos. No encontro das hélices, o esquema permite que certa atuação de um agente possa ser feita na área do outro, como, por exemplo, quando as universidades registram patentes ou as empresas realizam treinamentos. Estas atividades preveem a existência de uma infraestrutura de conhecimento, onde as instâncias envolvidas se sobrepõem originando organizações híbridas, que assumem as mesmas (ou similares) funções relativas à inovação tecnológica.

Ao ser comparado com os outros dois modelos propostos, o terceiro modelo possui uma "fraca" demarcação de limites de atuação entre as três esferas, em comparação aos outros dois modelos já expostos, que em conjunto com a sobreposição de responsabilidades por parte destes mesmos agentes, proporcionam o surgimento de uma interação dinâmica, onde os processos de inovação são intensificados.

Todas estas interações entre Universidade, Empresa e Governo, funcionam como base para as políticas de incentivo à inovação tecnológica de uma localidade, que segundo Kato (2008), são responsáveis por estabelecer o pilar da sociedade contemporânea.

\subsection{Relações Universidade - Empresa}

O processo de colaboração entre Universidades e Empresas surge do interesse de ambas as partes em trabalhar conjuntamente, a fim de angariar benefícios proporcionados pela coordenação dos esforços. Esta cooperação configura-se como um arranjo importante para o desenvolvimento da sociedade como um todo. 
Existe uma ligação direta entre o desenvolvimento das organizações e o desenvolvimento de uma sociedade. O desenvolvimento tecnológico, econômico e produtivo de uma empresa é capaz de gerar impactos na sociedade na qual ela se insere. E da mesma forma, quando uma sociedade se evolui é capaz de gerar benefícios para as empresas mediante a oferta de mão de obra mais qualificada.

\subsection{Motivações para cooperação entre universidades e empresas}

Segundo Tigre (2006) o desenvolvimento empresarial não deriva somente do crescimento das atividades econômicas existentes, mas reside fundamentalmente em um processo qualitativo da estrutura produtiva, no sentido de agregar novos produtos, processos e agregar valor à produção por meio da intensificação do uso da informação e do conhecimento. Para Jahara (2015) pensar na resolução de problemas exige a reflexão sobre o que é relevante e deve ser priorizado por garantir contribuição efetiva. Pensando nesta linha de raciocínio e correlacionando com as demandas locais e as do mercado de trabalho, se pode refletir sobre o tipo de produção científica de um curso de graduação e do perfil de egresso que está sendo formado.

Para Segatto-Mendes \& Sbragia (2002) o dinamismo contemporâneo tem aumentado a pressão exercida pelas forças do mercado sobre as empresas quanto à geração de resultados ante a escassez de recursos. O campo de Ciência e Tecnologia (C\&T) é um instrumento necessário para desenvolvimento de uma sociedade. As empresas contemporâneas acabam por figurar neste cenário como atores responsáveis por atender às demandas de uma sociedade. Segundo Nunes et al. (2015) na indústria, em seus distintos subsetores, a pesquisa desenvolvida em parceria com as universidades pode promover redução de custos e aperfeiçoamento das cadeias produtivas, tornando-as mais competitivas e possibilitando um maior enriquecimento do país. A partir de tais proposições pode-se inferir que às universidades compete exercer o papel de estimuladoras do desenvolvimento.

Segundo Tigre (2006), as universidades e os centros de pesquisas representam uma fonte independente de tecnologia, já que não estãoligados a empresas produtoras de bens e serviços. Assim, algumas das limitações observadas no comércio de tecnologia entre empresas podem não ocorrer nas relações universidade-empresa.

Torkomian (1997) realizou uma investigação para identificar, como na universidade, os grupos de pesquisa se organizam na geração e transferência de tecnologia na cooperação U-E. Entre os resultados destacaram-se:

- O principal motivo para o grupo trabalhar com pesquisa aplicada é o de poder contribuir com a sociedade;

- O principal resultado gerado pelas pesquisas é a formação de recursos humanos e melhoria da qualidade de ensino;

- O relacionamento com as empresas é tido como importante para que se possa aplicar o que é desenvolvido na universidade;

- Os principais ganhos para a universidade e para o pesquisador são os recursos financeiros e a geração de conhecimentos e obtenção de informações;

- O principal ganho para a empresa está na resolução de problemas; 
- Grande utilização, por parte dos pesquisadores, de canais intermediários.

Desta relação de cooperação surgem ainda outros benefícios como:

- Acesso das empresas a recursos humanos altamente qualificados pelas universidades;

- A redução dos riscos e custos das empresas com projetos de pesquisa;

- Acesso à conhecimentos atualizados provenientes do meio acadêmico;

- Identificação de talentos para incorporar o quadro de funcionários da empresa.

\section{METODOLOGIA}

Esta pesquisa é de natureza qualitativo-descritiva, de corte transversal, e de múltiplos casos. Dada a restrição de tempo e pessoas envolvidas na pesquisa, optou-se por estudar 10 empresas, abrangendo os três segmentos (Indústria, Comércio e Serviços), conferindo preferência pelas empresas de grande e médio porte. As empresas estudadas foram escolhidas seguin do o critério da amostragem por representatividade qualitativa, que é utilizado quando um grupo de indivíduos (neste caso, empresas) são selecionados de acordo com a sua relevância no problema a ser estudado. A seleção das empresas considerou vários aspectos, dentre os principais:

- empresas que, obrigatoriamente, estivessem inseridas no mesmo município que a IFES interiorizada na Região Metropolitana do Rio de Janeiro;

- empresas que possuem portfolio amplo de produtos e de abrangência nacional;

- empresas de setores distintos e de densidade econômica diferente entre si.

Nas palavras de Baptista e Campos (2010), o método de amostragem por representatividade ocorre quando os elementos a serem estudados foram escolhidos por conveniência (ou amostra qualitativa), ou seja, a amostragem foi não-probabilística, já que nem todos os elementos do universo tiveram probabilidade diferente de zero de serem selecionadas.

Com relação o questionário, segundo Gil (2002), caracteriza-se como uma das mais importantes técnicas para a obtenção de dados nas pesquisas. Um questionário pode ser definido como a técnica de investigação composta por um número de questões apresentadas por escrito às pessoas que estão inseridas no problema estudado.

As opções do questionário foram elaboradas de acordo com as ideias de Torkomian (1997). E o questionário foi elaborado seguindo o modelo proposto por Cervo et al. (2009):

- Identificar os dados ou as variáveis sobre os quais serão feitas as questões;

- Selecionar o tipo de pergunta a ser utilizada, visando quantificar as vantagens e desvantagens, de maneira que os dados possam ser tabulados e analisados;

- Elaborar perguntas referentes a cada dado a ser levantado;

- Elaborar instruções de preenchimento do formulário de forma clara e precisa;

- Revisar o formulário para dar ordem e sequência às questões abordadas.

Quanto ao tipo de perguntas, Baptista e Campos (2010) argumentam que existem dois: abertas (quando o pesquisador permite que o entrevistado responda a questão de forma livre, 
colhendo desta maneira informações com mais riqueza) e fechadas (quando a questão é formulada limitando suas respostas).

Nos questionários foram utilizadas perguntas abertas e fechadas, de modo a obter de maneira otimizada as respostas que o estudo pretende extrair. Preferencialmente, os questionários foram respondidos com o acompanhamento de ao menos um integrante do trabalho.

\subsection{Empresas estudadas}

Neste tópico serão apresentadas as empresas que participaram desta pesquisa propondo fornecer informações sobre sua localização, porte e ramo de atuação. A tabela 1 mostra uma síntese dessas informações, para posteriormente fornecer uma descrição mais detalhada de cada empresa.

Tabela 1: Síntese das informações sobre as empresas estudadas

\begin{tabular}{|c|c|c|}
\hline Empresas & Porte & Ramo \\
\hline Empresa A & Grande & Produção de cosméticos \\
\hline Empresa B & Grande & Produção de equipamentos para a área de limpeza urbana \\
\hline Empresa C & Médio & Produção de tintas, vernizes, esmaltes, massas e derivados \\
\hline Empresa D & Grande & Produção de molas automotivas \\
\hline Empresa E & Médio & Transporte rodoviário de passageiros \\
\hline Empresa F & Médio & Shopping Center \\
\hline Empresa G & Grande & Comercialização de medicamentos, e produtos de higiene e beleza \\
\hline Empresa H & Grande & Supermercados \\
\hline Empresa I & Grande & Comercialização de vários tipos de produtos \\
\hline Empresa J & Grande & Tratamento de resíduos \\
\hline
\end{tabular}

Empresa A: Fundada em 1986 e caracterizada como uma empresa de grande porte. Hoje, é uma das principais indústrias do setor de cosméticos do Brasil, faturando em 2011 cerca de $R \$ 528$ milhões. Além de possuir uma fábrica no centro de Nova Iguaçu, localizada a 8,1 km do CEFET-RJ UnED Nova Iguaçu, em 2010, inaugurou um centro de distribuição e uma fábrica de embalagens que fica a menos de $1 \mathrm{~km}$ do CEFET RJ UnED Nova Iguaçu. De acordo com os dados do Instituto de Pesquisa ACNielsen (2011), a empresa é líder em volume de vendas no segmento de coloração, além de estar entre as três maiores fabricantes de pós-shampoo e entre as cinco maiores fabricantes de shampoo do Brasil.

Empresa B: Criada há mais de 45 anos e caracterizada como uma empresa de grande porte. Destaca-se na produção de equipamentos para a área de limpeza urbana, como coletores de lixo, varredeiras e betoneiras. A empresa está localizada estrategicamente no eixo Rio-São Paulo, às margens da Via Dutra, em Nova Iguaçu, estando a uma distância de 7,6 km do CEFET-RJ UnED Nova Iguaçu.

Empresa C: Originada em 1924, se destaca no mercado de tintas, vernizes, esmaltes, massas e derivados. Atualmente, a empresa conta com duas unidades industriais: uma em Nova Iguaçu e outra em Queimados, sendo que a primeira delas está situada de 7,4 km da instituição de ensino estudada neste trabalho. Através da expansão da produção, fortalecimento da marca como 
sinônimo de qualidade e lançamentos de produtos inovadores, a empresa está caminhando para ser a maior fábrica de tintas do Rio de Janeiro e uma das maiores do Brasil.

Empresa D: Fundada em 1996, a empresa de grande porte, ocupa posição de destaque no mercado de molas automotivas, sendo hoje o maior fabricante de molas originais da América do Sul. Através de duas plantas, uma em São Bernardo do Campo, no Estado de São Paulo e outra em Nova Iguaçu que está localizada a 7,4 km do CEFET-RJ UnED Nova Iguaçu, a empresa se destaca na produção de molas helicoidais, feixes de molas e acessórios para suspensões automotivas. As duas plantas totalizam $31.000 \mathrm{~m}^{2}$ de área construída, em uma área total de $85.000 \mathrm{~m}^{2}$.

Empresa E: Fundada em 1951, na cidade de Nova Iguaçu, a empresa entrou em operação com uma pequena frota de apenas 12 veículos, cada um com capacidade para 20 passageiros. Hoje, esta empresa que atua no ramo de transporte rodoviário de passageiros, possui uma frota de 124 ônibus urbanos, mais de 600 funcionários e tem transportado cerca de meio milhão de pessoas por mês, operando em 12 linhas que ligam Nova Iguaçu ao Centro do Rio e Nova Iguaçu a Barra Mansa, via Volta Redonda, além de prestar serviços de turismo e fretamento.

Empresa F: Inaugurado em 1996, em Nova Iguaçu, é referência de consumo e lazer na baixada fluminense. Com $18.630 \mathrm{~m}^{2}$ de área bruta locável e $44.134 \mathrm{~m}^{2}$ de área construída, o shopping conta com três pisos de lojas e mais três pisos de estacionamento, oferecendo a seus clientes 136 operações em variados segmentos. Com a expansão do shopping através de um investimento inicial de 90 milhões, serão gerados cerca de 2000 empregos diretos e 850 temporários durante a construção. Após a conclusão das obras, o shopping ganhará 100 novas lojas e 1500 vagas a mais para estacionamento.

Empresa G: Com mais de 119 anos de atuação, é uma empresa que comercializa medicamentos e produtos de higiene e beleza. Contando com mais de 340 lojas distribuídas entre os Estados do Rio de Janeiro, Minas Gerais e Espírito Santo. Em 2011, para se tornar mais competitiva no segmento de varejo farma em consolidação no país, a empresa se fundiu com uma importante empresa que comercializa medicamentos no Estado de São Paulo, dando origem a uma nova companhia que é a maior empresa varejista de produtos farmacêuticos e a sétima maior rede de varejo do país, com 691 lojas, presente em 5 Estados brasileiros.

Empresa H: A empresa atua no ramo de supermercados e iniciou suas atividades em 1982 com uma loja em Nova Iguaçu. Hoje, decorridos 29 anos de sua fundação, são 17 lojas atendendo em Nova Iguaçu, Belford Roxo, Caxias, Nilópolis e Rio de Janeiro (Barra, Cascadura, Pavuna e Bonsucesso).

Empresa I: A empresa é uma das mais tradicionais redes de varejo do país. Com mais de 80 anos de vida, a empresa conta com 696 lojas nas principais cidades do país e com 3 centros de distribuição, em São Paulo, Rio de Janeiro e Recife, atuando também no comércio eletrônico. A rede comercializa mais de 60.000 itens de 4.000 empresas diferentes, o que faz com que a empresa detenha uma grande participação do comércio brasileiro de brinquedos, lingeries, CD's e DVD's e eletroportáteis.

Empresa J: Empresa de grande porte, que possui um Centro de Tratamento de Resíduos localizado à $6 \mathrm{~km}$ da instituição. No qual são realizados serviços de: Gerenciamento e tratamento de resíduos perigosos; Tratamento de resíduos industriais; Tratamento de resíduos urbanos; Tratamento de resíduos sólidos de serviços de saúde; Desenvolvimento de projetos de redução de 
gases de efeito estufa.

\section{RESULTADOS E DISCUSSÃO}

O universo das empresas pesquisadas é composto por empresas classificadas como de grande ou médio porte, que estão situadas em Nova Iguaçu, pertencentes aos setores s ecundários (indústrias) e terciários (serviços e comércio). Estes setores econômicos são os mais importantes para o resultado econômico da cidade.

$\mathrm{Na}$ escolha das empresas estudadas nesta pesquisa exploratória foi levado em consideração, além do porte, a atividade, o grau de importância da unidade empresarial localizada na cidade Nova Iguaçu para a empresa sede e a presença da marca na cidade de Nova Iguaçu. Deuse preferência às empresas constituídas nesta cidade, respeitando as premissas de porte e setor de atividade econômica.

A pesquisa procurou entrevistar dez empresas, sendo quatro empresas representantes do setor secundário (indústrias) e seis do setor terciário (comércio e serviços).

Essa divisão na quantidade de empresas que representam cada um dos setores foi feita de acordo com a participação de cada um destes na economia local indicada pelo Produto Interno Bruto (PIB) da cidade, com o ano de referência de 2010, último ano divulgado no portal das cidades do IBGE. De acordo com estes dados o setor terciário contribuiu com $77 \%$ do valor do PIB da cidade e, por este motivo o setor possui um número maior de representantes do que o setor secundário, que contribuiu com aproximadamente $13 \%$.

Para cada uma destas empresas foi submetido um questionário elaborado pelos autores do projeto e disposto no Anexo III deste trabalho. Os questionários foram aplicados pelo entrevistador, um dos autores do trabalho, a um entrevistado, representante da empresa, responsável pelo departamento de $\mathrm{RH}$ ou engenheiros. Quando não se mostrou possível aplicaro questionário com a presença do entrevistador, os questionários foram enviados aos entrevistados por correio eletrônico.

A análise das respostas às perguntas do questionário será feita de modo agrupado, sendo assim, as respostas das representantes da indústria e dos serviços será feita separadamente.

As perguntas dos questionários que foram enviados às empresas tinham por objetivo verificar qual é a percepção da empresa, expressa pelos seus representantes quanto aos seguintes temas:

- Importância de possuir engenheiros de produção em seu quadro de funcionários;

- Quais das competências de um engenheiro de produção, listadas pelo ENADE (2011), são mais importantes para as empresas tendo em vista as atividades desenvolvidas pela organização;

- O interesse da empresa em estabelecer relações com o CEFET-RJ UnED Nova Iguaçu através do material acadêmico e tecnológico produzido na instituição;

- O interesse das empresas em conhecer os cursos que são ofertados pela instituição de ensino supracitada; 
- Verificar se as empresas entrevistadas mantém ou já mantiveram relações trabalhistas com algum graduando ou graduado em Engenharia de produção pelo CEFET-RJ UnED Nova Iguaçu.

4.1 Avaliação da importância de um engenheiro de produção para as empresas estudadas

Quando as empresas foram questionadas sobre a importância de possuir um profissional graduado em engenharia de produção em seu quadro de funcionários, $90 \%$ das empresas apontaram que a presença deste tipo de profissional é de grande importância para as atividades por elas desenvolvidas, como pode ser observado na Figura 2.

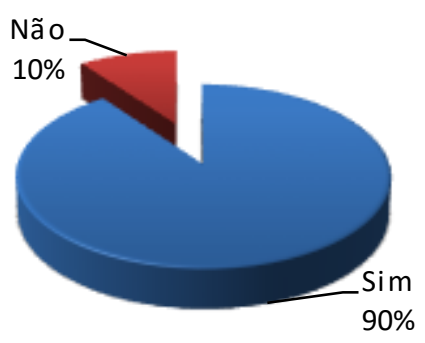

Figura 2: Percentual de empresas que acham importante possuir um engenheiro de produção.

Dentre todas as empresas estudadas apenas uma delas afirmou que não é importante possuir um engenheiro de produção. A empresa $\mathrm{F}$ afirmou que as atividades que desempenha não necessitam tal qualificação.

Dos $90 \%$ dos entrevistados que relataram a importância de possuir um profissional graduado em engenharia de produção, todos confirmaram a contribuição deste profissional para otimizar o desempenho das empresas. A empresa $D$, metalúrgica, fabricante de molas, ratificou esta importância classificando-a como extrema para o sucesso das operações realizadas em sua unidade fabril situada em Nova Iguaçu.

Após a avaliação sobre o grau de importância de um engenheiro de produção para a empresa, os entrevistados foram solicitados a darem notas de 1 a 5 para competências de um profissional graduado em engenharia de produção, segundo o ENADE (2011).

Nesta avaliação a nota 1 significa que a competência não é importante para a empresa e 5 significa que a competência é muito importante. A fim de obter um índice de importância de cada competência para as empresas, foi criado um indicador que pode assumirvalores entre 0 e 1 , onde zero representa o mínimo grau de importância e 1 apresenta o grau máximo. As competências para as quais as empresas deveriam qualificar através das notas são:

C1: Aperfeiçoar produtos, processos e sistemas de produção e serviços;

C2: Aplicar práticas que aumentem a produtividade e a qualidade dos produtos, de modo a reduzir custos através de melhorias contínuas no processo e/ou produto;

C3: Otimizar o fluxo de informações e de materiais;

C4: Produzir normas e procedimentos de monitoração, controle e auditoria; 
C5: Prever e analisar as demandas de mercado, de modo a adequar o perfil da produção e dos produtos a elas;

C6: Prever a evolução dos cenários produtivos, atuando no planejamento organizacional e na posição estratégica da empresa;

C7: Compreender a inter-relação entre produtos, processos, sistemas de produção de modo que os mesmos atendam às exigências de sustentabilidade;

C8: Construir modelos e avaliar o desempenho de sistemas de produção;

C9: Desenvolver e implantar inovações organizacionais e tecnologias de gestão.

A tabela 2 apresenta o resultado do índice obtido separado por indústria, comércio e serviços e ao final será apresentado o índice final que foi obtido pela média entre os índices de cada setor econômico.

Tabela 2 - Índices de importância das competências de um engenheiro de produção por setor.

\begin{tabular}{|c|c|c|c|}
\hline Competência & $\begin{array}{c}\text { Indicador } \\
\text { Indústria }\end{array}$ & $\begin{array}{c}\text { Indicador } \\
\text { Serviços }\end{array}$ & $\begin{array}{c}\text { Indicador } \\
\text { Comércio }\end{array}$ \\
\hline C1 & 0,6250 & 0,8750 & 1,0000 \\
\hline C2 & 0,9375 & 1,0000 & 0,9167 \\
\hline C3 & 0,7500 & 1,0000 & 0,6667 \\
\hline C4 & 0,4375 & 0,5000 & 0,8333 \\
\hline C5 & 0,4375 & 0,7500 & 0,5000 \\
\hline C6 & 0,4375 & 0,7500 & 0,7500 \\
\hline C7 & 0,8125 & 0,8750 & 0,8333 \\
\hline C8 & 0,5625 & 0,8750 & 0,7500 \\
\hline C9 & 0,5000 & 0,7500 & 0,9167 \\
\hline
\end{tabular}

Na Tabela 3 é possível observar que as empresas atribuíram maior grau de importância às competências que estão ligadas aos processos de produção e controle. O maior índice está associado à adoção de práticas que possibilitem o aumento da produtividade; a segunda competência de maior valor segundo os entrevistados está na construção de modelos e métodos de avaliação e controle; a terceira maior nota foi conferida a aperfeiçoar processos e sistemas de produção e serviços. Em suma, os resultados apontam que a competência mais valorizada pelas empresas em um engenheiro de produção é a de otimização dos processos de produção.

Tabela 3 - Índice médio da importância das competências de um engenheiro de produção para as empresas estudadas.

\begin{tabular}{|c|c|}
\hline Competência & Índice Médio \\
\hline C2 & 0,9514 \\
\hline C7 & 0,8403 \\
\hline C1 & 0,8333 \\
\hline C3 & 0,8056 \\
\hline C8 & 0,7292 \\
\hline C9 & 0,7222 \\
\hline C6 & 0,6458 \\
\hline C4 & 0,5903 \\
\hline C5 & 0,5625 \\
\hline
\end{tabular}


4.2 Nível de conhecimento das empresas entrevistadas sobre as atividades desenvolvidas pelo CEFET de Nova Iguaçu

Quando as empresas foram questionadas sobre os cursos ofertados pelo CEFET de Nova Iguaçu, $60 \%$ dos entrevistados não sabiam que a referida instituição oferece cursos de graduação em engenharia. Destas empresas todas afirmaram saber dos cursos técnicos ofertados pela instituição.

Dos $40 \%$ que afirmaram conhecer os cursos ofertados, todas são empresas que já ofertaram estágio para algum graduando do curso de engenharia de produção. Um fato importante de salientar é que muitas das vezes a instituição se torna conhecida através da iniciativa dos alunos, que sem o apoio oficial ou a contribuição da instituição de ensino, buscam estas oportunidades de emprego.

Um dos canais que os cursos de graduação do CEFET-RJ UnED Nova Iguaçu possuem é um grupo de e-mail onde alunos e professores trocam mensagens, fazem os anúncios e enviam oportunidades de trabalho. Muitas destas oportunidades acabam sendo aproveitadas, contribuindo para a empregabilidade dos alunos.

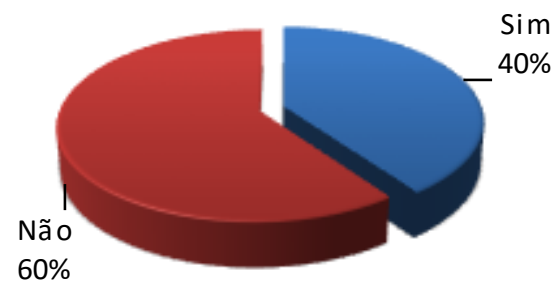

Figura 3: Percentual de empresas que conhecem os cursos de graduação ofertados no CEFET Nova Iguaçu.

A empresa I, quando entrevistada, disse que passou a conhecer o CEFET quando contratou um estagiário que cursava Engenharia de Produção e relatou que devido ao excelente desempenho deste aluno passou a conhecer a instituição e que está à procura de estagiários com as mesmas competências. Contudo, cabe ressaltar que esta forma de campanha é válida e capaz de propagar o conhecimento sobre a instituição, entretanto, ocorre em escala muito menor do que se esta iniciativa ocorresse com o apoio e a intervenção da instituição de ensino.

O questionário também inquiriu os entrevistados se os mesmos já tiveram acesso a algum trabalho publicado por alunos ou professores do CEFET de Nova Iguaçu. Apenas uma das empresas afirmou já ter acessado materiais publicados e completaram que gostariam de ter acesso a estes materiais, principalmente aos trabalhos publicados nas áreas de conhecimento que possuem relação direta com as atividades desempenhadas pelas empresas.

As empresas também foram perguntadas se já foram base de algum trabalho desenvolvido por alunos da instituição. Apenas duas das empresas (Empresa J e Empresa A) afirmaram já ter sediado alguma pesquisa realizada por alunos ou professores do CEFET de Nova Iguaçu. A Empresa J se mostrou satisfeita e interessada em estabelecer um novo trabalho de pesquisa.

Todas as empresas disseram que nunca foram base de pesquisa afirmaram que o acesso à empresa para realizar estes trabalhos é uma questão negociável com a gerência e se mostraram favoráveis ao desenvolvimento destas atividades. 
Outro fator importante é que dentre as empresas entrevistadas três já tiveram estagiários que cursavam Engenharia de Produção no CEFET-RJ UnED Nova Iguaçu. A pesquisa evidencia que, apenas uma destas empresas possui estagiários que estão cursando Engenharia de Produção na instituição de ensino em questão, sendo que nenhuma destas empresas emprega ou já empregou engenheiros de produção formados pelo CEFET de Nova Iguaçu.

Esta informação evidencia que o valor que tem sido agregado aos alunos através da transferência de conhecimento, feita durante toda a formação dos alunos, não tem sido aproveitado localmente. Embora a formação destes engenheiros esteja ocorrendo na cidade de Nova Iguaçu, os egressos estão sendo absorvidos pela demanda de outras regiões, principalmente a cidade do Rio de Janeiro.

4.3 Percepção das empresas sobre a relação de parceria entre universidade e empresa

O último aspecto a ser avaliado pelas empresas no questionário era referente à opinião das empresas sobre a relação de parceria entre universidade e empresa (U-E). No âmbito do estabelecimento deste tipo de relação, os entrevistados foram perguntados quais aspectos seriam de maior interesse para suas empresas, em caso de estabelecimento de relação de parceria com o CEFET-RJ UnED Nova Iguaçu. Os entrevistados possuíam as seguintes opções:

- $\quad$ Pesquisas encomendadas;

- $\quad$ Oportunidade de trabalho;

- Transferência de tecnologia;

- $\quad$ Trabalhos Pontuais;

- Não possui interesse.

Os entrevistados poderiam marcar mais do que uma opção ou indicar que não possuíam interesse, sendo que apenas a Empresa $\mathrm{F}$ indicou não possuir interesse no estabelecimento deste tipo de parceria. O resultado obtido para esta questão é apresentado na Figura 4.

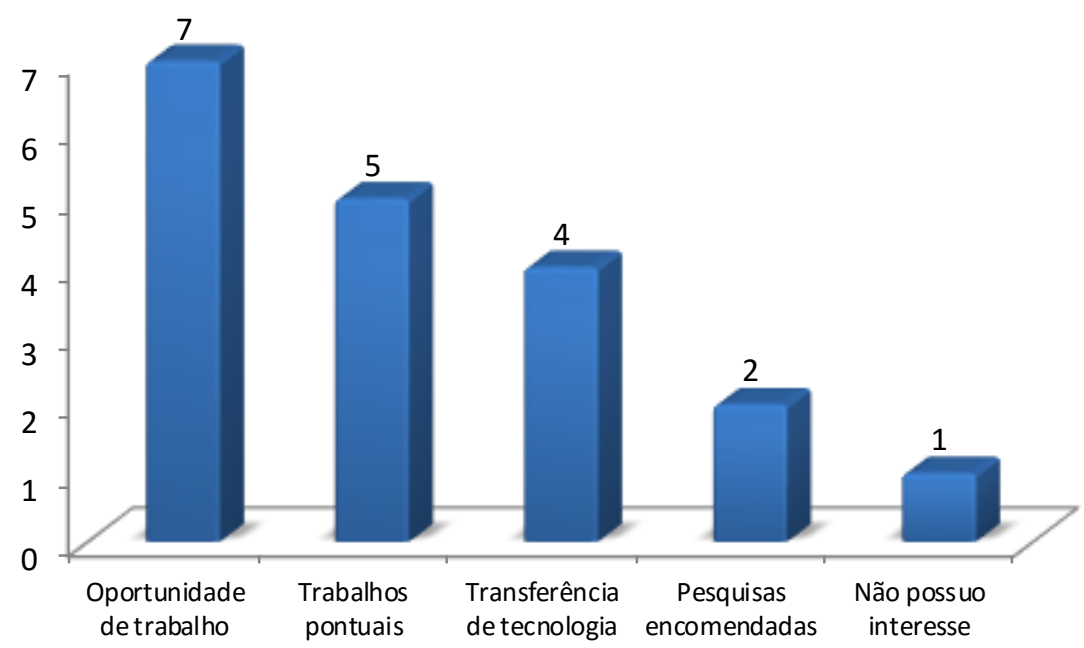

Figura 4: Interesse das empresas para estabelecimento de relação de parceria U-E.

Os resultados obtidos indicam que o maior dos interesses destas empresas entrevistadas é para o estabelecimento de parceria entre universidades e empresas para a geração de 
oportunidades de trabalho. De acordo com estes dados, os trabalhos pontuais seriam o segundo maior interesse para as empresas, entende-se por trabalhos pontuais aqueles que visam à solução de algum problema específico na empresa.

A Figura 5 apresenta os resultados obtidos para a referida pergunta, separando os resultados por setor de atividade econômica. Observa-se que o setor de comércio possui maior interesse na geração de oportunidade de trabalho, enquanto a indústria possui interesse em trabalhos pontuais e transferência de tecnologia. Já setor de serviços se dividiu entre a transferência de tecnologia e oferta de oportunidade de trabalho.

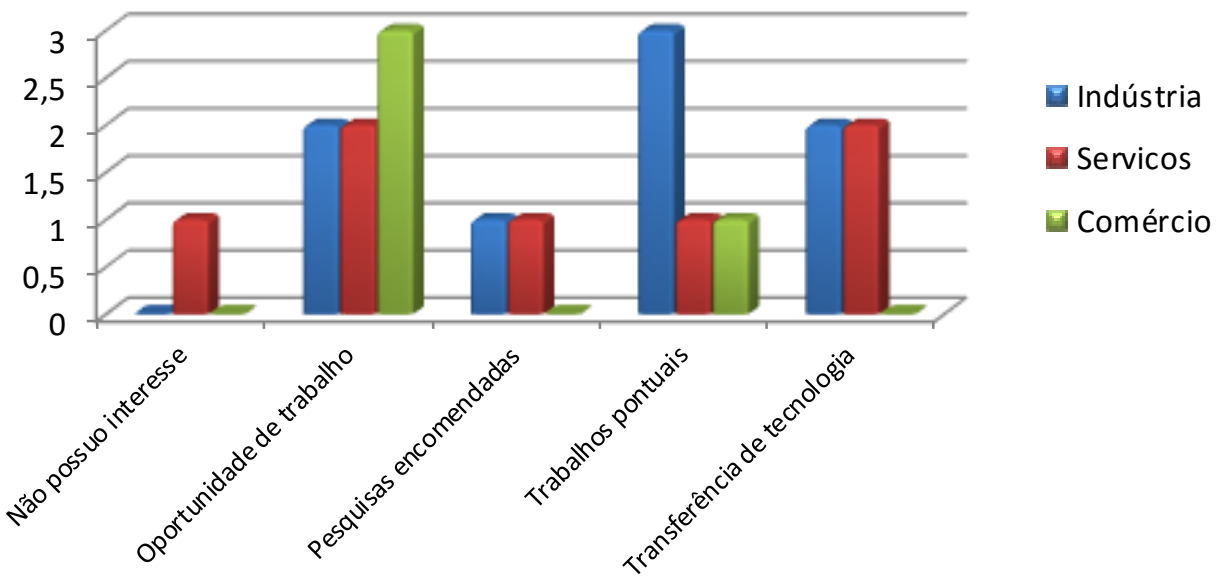

Figura 5: Interesse das empresas para estabelecimento de relação de parceria U-E, por setor econômico.

As empresas também foram questionadas sobre qual seria o fato que mais motivaria o estabelecimento de uma parceria com o CEFET-RJ UnED Nova Iguaçu.

Desta forma os entrevistados foram solicitados a dar notas a cada um dos tipos de motivação para a instalação de parceria entre universidade e empresa. Os resultados à pergunta foram obtidos, calculados e apresentados na tabela 4 .

As motivações que as empresas deveriam qualificar são:

M1: Acesso das empresas à recursos humanos altamente qualificados pelas universidades;

M2: A redução dos riscos e custos das empresas com projetos de pesquisa;

M3: Acesso à conhecimentos atualizados provenientes do meio acadêmico;

M4: Identificação de talentos para incorporar ao quadro de funcionários da empresa.

Tabela 4: Motivadores para a instauração de parceria das empresas com o CEFET Nova Iguaçu.

\begin{tabular}{|c|c|}
\hline Motivador & Índice Médio \\
\hline M1 & 0,8542 \\
\hline M4 & 0,8472 \\
\hline M3 & 0,7500 \\
\hline M2 & 0,6597 \\
\hline
\end{tabular}

O resultado obtido é que os principais fatores que motivariam esta relação seriam relativos à identificação de profissionais qualificados para serem aproveitados pelas empresas. Já a tabela 5 
mostra os resultados do índice de análise obtidos para cada opção motivadora, por setor de atividade.

Tabela 5: Motivadores para a instauração de parceria das empresas com o CEFET Nova Iguaçu, por setor.

\begin{tabular}{|c|c|c|c|}
\hline Motivador & $\begin{array}{c}\text { Indicador } \\
\text { Indústria }\end{array}$ & $\begin{array}{c}\text { Indicador } \\
\text { Serviços }\end{array}$ & $\begin{array}{c}\text { Indicador } \\
\text { Comércio }\end{array}$ \\
\hline M1 & 0,6875 & 0,6250 & 0,6667 \\
\hline M2 & 0,7500 & 0,7500 & 0,7500 \\
\hline M3 & 0,5625 & 1,0000 & 1,0000 \\
\hline M4 & 0,7500 & 0,8750 & 0,9167 \\
\hline
\end{tabular}

Dando sequencia, às empresas foi solicitado fornecer notas de 1 a 5 para as seguintes barreiras para o estabelecimento das parcerias entre universidades e empresas:

B1: Burocracia em estabelecer uma união entre Universidades e Empresas;

B2: Instabilidade das universidades públicas, que por vezes são paralisadas por conta de greves, falta de pagamento e afins;

B3: Incerteza das pesquisas convergirem para algo utilizável pela empresa;

B4: Extensão do tempo da pesquisa, tendo em vista que em muitos casos, o tempo investido em procedimentos metodológicos e pesquisas de campo, acabam por aumentar o tempo do projeto;

B5: Busca do conhecimento fundamental pela universidade, o qual preza pela ciência básica e não o desenvolvimento ou a comercialização dos avanços obtidos.

É possível notar com a tabela 6 que os indicadores para a importância das barreiras foram muito menores em comparação com os índices registrados nos elementos motivadores.

Tabela 6: Barreiras para a instauração de parceria das empresas com o CEFET Nova Iguaçu.

\begin{tabular}{|c|c|}
\hline Barreiras & Índice Médio \\
\hline B2 & 0,7083 \\
\hline B1 & 0,5903 \\
\hline B4 & 0,5556 \\
\hline B3 & 0,4931 \\
\hline B5 & 0,4097 \\
\hline
\end{tabular}

Este resultado aponta que, na avaliação dos entrevistados, as barreiras listadas possuem menor relevância do que o benefício que é gerado pela instauração da parceria.

Na tabela 7 se apresenta que os entrevistados foram questionados sobre o que, na opinião deles poderia ser feito pelo Estado, como terceiro agente no processo da criação de relacionamento entre universidades e empresas, defendido no modelo de relacionamento triplehelix. 
Tabela 7: Barreiras para a instauração de parceria das empresas com o CEFET Nova Iguaçu por setor.

\begin{tabular}{|c|c|c|c|}
\hline Barreiras & $\begin{array}{c}\text { Indicador } \\
\text { Indústria }\end{array}$ & $\begin{array}{c}\text { Indicador } \\
\text { Serviços }\end{array}$ & $\begin{array}{c}\text { Indicador } \\
\text { Comércio }\end{array}$ \\
\hline B1 & 0,5625 & 0,3750 & 0,8333 \\
\hline B2 & 0,8750 & 0,5000 & 0,7500 \\
\hline B3 & 0,4375 & 0,3750 & 0,6667 \\
\hline B4 & 0,7500 & 0,5000 & 0,4167 \\
\hline B5 & 0,4375 & 0,3750 & 0,4167 \\
\hline
\end{tabular}

A Burocracia em estabelecer uma união entre Universidades e Empresas e a instabilidade das universidades públicas, que por vezes são paralisadas por conta de greves, e afins, é o que surge com pontos mais desfavoráveis.

\section{CONCLUSÕES}

O presente trabalho buscou estudar como a relação de parceria entre universidade e empresa pode contribuir para o aumento da empregabilidade local dos alunos e egressos de uma instituição federal de ensino superior recém-instalada na cidade de Nova Iguaçu e avaliar como este tipo de parceria pode gerar oportunidades e benefícios para ambas às partes no compartilhamento de conhecimentos e transferência de tecnologia.

A maioria das empresas disse que o Estado poderia conferir algum benefício fiscal para a contratação da mão de obra recém-formada. As empresas mencionaram a diminuição de alguns impostos como um ponto que seria um grande facilitar para o estabelecimento das parcerias para contratação dos profissionais recém-formados pelo CEFET-RJ UnED Nova Iguaçu.

Os resultados da pesquisa exploratória com as empresas apontaram que os cursos de graduação em engenharia ofertados pela instituição ainda não são amplamente conhecidos. As empresas disseram ter conhecimento dos cursos de nível técnico que são ofertados, contudo, mais da metade dos entrevistados não tinha conhecimento de que cursos de nível superior em engenharia de produção são ofertados na instituição de ensino em questão.

Apenas uma das empresas (Empresa F) que participou da pesquisa afirmou não ter necessidade de um engenheiro de produção em seu quadro de funcionários. As demais empresas se mostraram interessadas em conhecer os cursos de Engenharia do CEFET-RJ UnED Nova Iguaçu e em ter acesso aos materiais acadêmicos produzidos pela instituição que sejam relativos aos ramos de atividade das empresas.

O motivo de maior interesse das empresas em estabelecer as relações de parceria com o CEFET de Nova Iguaçu, segundo os resultados da pesquisa, é ter acesso a recursos humanos altamente qualificados na universidade.

Segundo as mesmas, as competências de um engenheiro de produção que mais as interessam estão relacionadas à otimização de processos e sistemas de produção. As empresas indicaram que as capacidades de conferir maior produtividade e reduzir custos são as competências mais desejadas neste profissional. 
Um dos fatores mais determinantes para se instituir uma parceria Empresa- Universidade, é a relação de ganha - ganha apresentada nesta união, ou seja, quando onde os benefícios da cooperação entre universidades e empresas são obtidos por ambas as partes.

\section{REFERENCIAS}

1. BAPTISTA, M.N.; CAMPOS, D.C. Metodologias de Pesquisa em Ciências: Análises Quantitativa e Qualitativa. Rio de Janeiro: LTC, 2010.

2. CASADO, F.L; ZAMPIERE, N.L.V; SILUK J.C.M. Programa de promoção da Universidade Empreendedora para o desenvolvimento sustentável. Fundação Antonio Meneghetti \& Faculdade Antonio Meneghetti - Recanto Maestro, 2011.

3. CERVO, A.L.; BERVIAN, P.A.; DA SILVA, R. Metodologia Científica. São Paulo: Pearson, 2009.

4. CUNHA, S.K.; NEVES, P. Aprendizagem Tecnológica e a Teoria da Hélice Tripla: Estudo de caso num APL de Louças. Disponível em: < http://pt.scribd.com/doc/17022738/APLs-Triangulo-deSabato-e-Tripla-Helice >. Acessado em: 17 de Julho de 2012.

5. DOSSA, A.A; SEGATTO, A.P. Pesquisas cooperativas entre universidades e institutos públicos no setor agropecuário brasileiro: um estudo na Embrapa. Revista de Administração Pública, vol. 44, núm. 6, novembro-dezembro, 2010, pp. 1327-1352.

6. GIL, A.C. Como elaborar projetos de pesquisa. 4. ed. São Paulo: Atlas, 2002.

7. KATO, E.M. Processos de Comunicação em Cooperações Tecnológicas Universidade-Empresa: Estudo de Caso Múltiplos. Dissertação (Mestrado em Administração) Universidade Federal do Paraná, Curitiba: Paraná, 2008.

8. JAHARA, R.C., SOUZA, G.M., MELLO, A.J.R., PEIXOTO, A.B.M., SOUZA, A.L.L. Contribuições dos trabalhos de fim de curso de engenharia de produção de uma unidade de ensino descentralizada. Revista Produção e Desenvolvimento, v.1, n.3, p.15-28, set./dez., 2015

9. NOVELI, M.; SEGATTO, A.P. Processo de cooperação Universidade-Empresa para a Inovação Tecnológica em um Parque Tecnológico: Evidências Empíricas e Proposição de um Modelo Conceitual. Revista de Administração e Inovação, São Paulo, v. 9, n.1, p. 81-105, jan ./ mar. 2012.

10. NUNES, C.F., WEISE, A.D., MEDEIROS, F.S.B. Uma proposta de alinhamento das áreas de pesquisa em um programa de pós-graduação em engenharia de produção. Revista Produção e Desenvolvimento, v.1, n.2, p.44-55, mai/ago, 2015

11. SEGATTO-MENDES, A. P., \& SBRAGIA, R. O processo de cooperação universidade-empresa em universidades brasileiras. Revista de Administração, 37(4), 58-71, 2002.

12. TIGRE, P. Gestão da Inovação: A economia da tecnologia no Brasil. Rio de Janeiro: Elsevier, 2006.

13. TORKOMIAN, A.L. Gestão de Tecnologia na Pesquisa Acadêmica: O Caso de São Carlos. Tese (Doutorado em Administração de Empresas) FEA/USP - Faculdade de Economia, Administração e Contabilidade - Universidade de São Paulo, São Paulo, 1997. 